AEA, LXXVII, 2004, 305, pp. 75 a 97. ISSN: 0004-0428

\title{
VARIA
}

\section{NUEVA INFORMACIÓN SOBRE ALONSO CANO}

Como aportación documental al cuarto centenario del nacimiento del pintor, escultor y arquitecto granadino Alonso Cano (1601-1667) presentamos una nueva noticia que esperamos ayude en futuras investigaciones a precisar aún más sobre la vida y obra de tan destacado genio '.

En contadas ocasiones hallamos testimonio escrito donde se efectúa un contrato artístico para una clientela particular al margen de los habituales encargos eclesiásticos o reales en torno a los pintores españoles del siglo XVII ${ }^{2}$. El 28 de mayo de 1660 Cano concierta en Madrid la elaboración de una nueva obra dentro de su producción pictórica ${ }^{3}$. Licenciado, Racionero de la Santa Iglesia de Granada y Procurador Fiscal de la Cámara Apostólica de esta ciudad, se omite a priori junto a estos oficios su profesión por la pintura. El encargo se efectúa por orden de Blas López, un maestro del arte de escribir del que hasta el momento carecemos de más información. Mediante convenio se especifica que Alonso Cano «le halla de hacer de pintura un cuadro con dos figuras, la una de Nuestro Señor tendido en el regazo de Nuestra Señora, que a de ser la otra figura» con unas medidas de «dos varas y media de ancho y dos varas de alto». La obra será entregada en «octubre que viene de este presente año» y su coste será de mil reales de vellón haciéndose el pago mediante «diferentes alhajas y estampas». Tras el protocolo habitual en este tipo de contratos aparecen como testigos Tomás de Almansa y la Plaza, Juan Ruiz y Juan Álvarez ${ }^{4}$. Estos tienen que ser llamados por Cano, López o el propio Almansa, ya que ninguno de ellos es testigo habitual que trabaje con Pedro de Viana Morales, escribano del rey ante el cual se protocoliza el acto.

El encargo a realizar se trata, suponemos, de una Piedad sobre lienzo de formato rectangular horizontal de aproximadamente $166 \mathrm{~cm}$ de alto por $207,5 \mathrm{~cm}$ de ancho ${ }^{5}$. La pintura tendría unas dimensiones prácticamente similares a trabajos como Primera labor de Adán y Eva

\footnotetext{
1 Véase Pita Andrade, J. M. (dir.); Aterido, A. (ed.): Corpus Alonso Cano. Madrid, Dirección General de Bellas Artes, 2.002. Mi agradecimiento a Ángel Aterido por posibilitar mi labor en la colaboración científica de esta obra.

${ }^{2}$ En el caso de Cano pintor, además de la relación artística con su padre Miguel Cano y exceptuando sus pinturas para Felipe IV, tenemos las obras: «Mártires del Japón» de 1.627 para el Duque de Medina Sidonia; «Cristo y la Virgen con santos» de 1.630 para el escultor Luis Ortiz de Vargas; y tres retratos de 1.645 pendientes de cobrar entonces a través de Sebastián Vicente, Secretario del Rey. (Pita y Aterido: ob. cit., pp. 82, 123-125 y 277).

${ }^{3}$ Archivo Histórico de Protocolos de Madrid (A.H.P.M.): p ${ }^{\circ} 8.553$, fols. 255 y v. Presentado en Pita y Aterido: $o b . c i t$, n. ${ }^{\circ} 369 a$, pp. $400-401$ y 637.

${ }^{4}$ Del primero, único testigo firmante, desconocemos si tendrá vínculos familiares con María de Almansa, madre del artista. El segundo es homónimo del beneficiario, ya en Granada, que aparece en el memorial de deudas previo al testamento de Cano (véase Pita y Aterido, ob. cit., p. 453).

${ }^{5}$ Tomando 1 vara castellana $=83 \mathrm{~cm}$.
} 
$(166 \times 207 \mathrm{~cm})$ de la colección Pollock House en Glasgow o Cristo y la Samaritana $(166 \times$ $205 \mathrm{~cm}$ ) de la Real Academia de Bellas Artes de San Fernando en Madrid ${ }^{6}$. El contrato detalla que sólo aparecerán «dos figuras, la una de Nuestro Señor tendido en el regazo de Nuestra Señora, que ha de ser la otra figura del dicho cuadro», sin informar acerca de la presencia de otros personajes que tradicionalmente aparecen en este tipo de composición. De mano de Cano con esta iconografía es obra conocida la pintura titulada por Wethey Lamentación que se conserva en el Museo Cerralbo de Madrid, obra de mayores dimensiones y complejidad compositiva que la que aquí suponemos ${ }^{7}$. Para Wethey, el lienzo de este museo «fue probablemente pintado por Alonso Cano tras su regreso a Granada en 1660, debido a las copias y a las versiones que se encuentran en iglesias y colecciones granadinas». Puso además este tema en relación con el grabado de Schelte à Bolswert, que como es bien sabido, copia el original vandyckiano Piedad del Musée des Beaux-Arts de Amberes cuya influencia Navarrete Prieto ilustra añadiendo un caso más ${ }^{8}$. Si Cano se inclinara por desarrollar este modelo iconográfico sería lógico pensar que, además del obligado formato de la pintura a realizar, utilizase una vez más y de modo simplificado, todavía en Madrid, este grabado para el nuevo encargo.

Su gusto por las estampas queda reflejado en su interés personal por adquirir este tipo de herramientas de trabajo ${ }^{9}$. La provisión que realiza de los grabados que en su día pertenecieron a otros pintores como Vicente Carducho, Antonio Puga o Domingo Guerra Coronel no se va a limitar sólo a la compra en las almonedas que se efectuaron tras sus respectivos fallecimientos ${ }^{10}$; Cano exigirá, como ocurre en este nuevo documento, que el pago por la nueva pintura se realice «en [tachado: dinero de contado de] diferentes alhajas y estampas y mediante ellas se da por entregado de los dichos mil reales por haberlas recibido a su satisfacción» ${ }^{11}$. La cuantía total en reales es considerable sólo si la comparamos con los pagos que Cano efectuó por las estampas y algunos dibujos en estas almonedas ${ }^{12}$. El grueso de esta cantidad lo formarían, por tanto, las alhajas no citadas en esta fuente documental.

La relación entre Alonso Cano y la estampa como fuente compositiva fue dada ya a conocer por Antonio Palomino, quién al tratar sobre la vida del granadino, apunta: «No era melindroso nuestro Cano, en valerse de las estampillas más inútiles, aunque fuesen de unas coplas; porque quitando, y añadiendo, tomaba de alli ocasión, para formar conceptos maravillosos; y motejándole esto algunos pintores por cosa indigna de un inventor eminente, respondía: 'Hagan ellos otro tanto, que yo se lo perdono'. Y tenía razón, porque esto no era hurtar, sino tomar ocasión; pues por última, lo que él hacía, ya no era, lo que había visto» ${ }^{13}$.

${ }^{6}$ Para estas dos pinturas, véase: Alonso Cano. Espiritualidad y modernidad artística. Catálogo exposición. Granada, 2001-2002, pp. 260-261, 270-271, 416-417 y 434- 435. Véase Alonso Cano. La modernidad del Siglo de Oro. Catálogo exposición. Madrid, del 1 de abril al 26 de mayo de 2002, pp. 144-145 y 146-147.

${ }^{7}$ Wethey, H. E.: Alonso Cano. Pintor, escultor y arquitecto. Madrid, 1.983, pp. 52, 91, 119-120, 182 y láms. 123 y 125.

${ }^{8}$ Véase Navarrete Prieto, B.: La pintura andaluza del siglo xvIr y sus fuentes grabadas. Madrid, 1998, pp. 200, $201-202$ y 320.

${ }^{9}$ Véase Navarrete Prieto, B. y Salort Pons, S.: «El saber de un artista: Fuentes formales y literarias en la obra de Alonso Cano». En Alonso Cano. Espiritualidad y modernidad artística, ob. cit., pp. 129-151. Véase asimismo este capítulo en Alonso Cano. La modernidad del Siglo de Oro, ob. cit., pp. 47-64. Véase Véliz, Z.: «Alonso Cano dibujante». En Alonso Cano. Dibujos. Catálogo exposición. Madrid, del 2 de abril al 24 de junio de 2001, pp. 34, 35 y 53.

${ }^{10}$ Véase: Pita y Aterido, ob. cit., pp. 245, 283 y 302. Para Carducho, véase Caturla, M. ${ }^{a}$ L.: «Documentos en torno a Vicencio Carducho». En Arte Español, t. XXVI, 1968-69, p. 215. (A.H.P.M.; po 5.023, fol. 406). Para Puga, véase Caturla, M. ${ }^{a}$ L.: «Un pintor gallego en la Corte de Felipe IV. Antonio Puga». En Cuadernos de Estudios Gallegos, anejo VI, 1952, pp. 62 y 63. (A.H.P.M.; po 7.102, fols. 102 y 103 del año 1648). Para Guerra, véase Saltillo, M. de: «Un pintor desconocido del siglo xvir: Domingo Guerra Coronel». En Arte Español, t. XV, 1944-45, p. 46. (A.H.P.M.; p 6.766, fols. 550 y v). De modo general, Navarrete, ob. cit., pp. 83 y 312; y Wethey, ob. cit., pp. 51-52 y 103-104.

"A.H.P.M.; ob. cit., fol. 255. En el documento aparece tachado «dinero de contado de», bien a un último cambio en la forma de pago, bien a un error por escritura del escribano.Ver apéndice documental al final del artículo.

${ }^{12}$ En la almoneda de Carducho pagó un parcial de 46 3/4 rs.; en la de Puga, 45 rs.; en la de Guerra, 18 rs.

${ }^{13}$ Palomino de Castro y Velasco, A. A.: El Museo Pictórico y escala óptica. T. III de El Parnaso español pintoresco laureado. Madrid, 1724. Otra ed., Madrid, 1988, p. 348.

$A E A$, LXXVII, 2004, 305, pp. 75 a 97 
La única obra conocida hasta la fecha que puede relacionarse directamente con la Piedad contratada en el documento causa de este estudio es un lienzo expuesto en una de las recientemente renovadas salas del Museo de la Real Academia de Bellas Artes de San Fernando en Madrid (fig. 1) ${ }^{14}$. Su época, autoría, temática y condiciones del contrato coinciden prácticamente con la pintura a ejecutar. Las medidas que se especifican entre este contrato y esta pintura son análogas ${ }^{15}$. Pérez Sánchez lo catalogó en su inventario de $1.964{ }^{16}$ como obra de Alonso Cano. La bibliografía al respecto, desde sus primeros catálogos impresos, coincide en dicha autoría ${ }^{17}$. Ponz, en su visita a la iglesia de los Jesuitas en Cuenca, localiza y describe esta misma pintura indicando su traslado a la Academia sin dudar sobre su autor: «En la sacristía hay un bellísimo cuadro de Jesucristo muerto, recostado en brazos de Su Santísima Madre, figura expresiva. (...) Hoy está como los de Cincinnato en la casa de la Real Academia de San Fernando, y es original de Alonso Cano» ${ }^{18}$. No tenemos noticias de que Cano trabajase de manera directa para este templo conquense. De tratarse del lienzo pintado por encargo de Blas López, su ingreso en aquella comunidad se efectuaría por donación, deuda u otra vía de acceso. Sea como fuere planteamos que Alonso Cano, continuando con su admiración por la escuela flamenca y en particular por la obra de Van Dyck, tome como fuente de inspiración para esta nueva pintura otro modelo iconográfico sobre el tema de la piedad. De su conocimiento de variantes sobre este asunto pueden establecerse dos fuentes que nuevamente inspirasen al pintor: la primera y más común, por mediación de otras estampas; la segunda, nuestra hipótesis, por el conocimiento directo de una pintura concreta. A este respecto proponemos la observación directa que Cano pudo realizar sobre la Piedad de Van Dyck, entonces en el monasterio de San Lorenzo el Real de El Escorial, y que hoy guarda el Museo Nacional del Prado en Madrid (fig. 2) ${ }^{19}$.

${ }^{14}$ N. ${ }^{\circ}$ inv. 74. Número manuscrito «136.» anotado en etiqueta cuadrangular pegada sobre el lienzo, probablemente a la fecha de ingreso en la Academia. Óleo sobre lienzo con bastidor y marco liso y dorado ambos en madera de pino sustituidos en el s. XIX. Lienzo reentelado durante el s. XIX. Papel pegado en el bastidor haciendo referencia a la exposición de Cano en Granada, junio-julio de 1954 con núm. 006. Mi agradecimiento a M. a Ángeles Blanca Piquero López y Beatriz Barchino por su atención prestada. Foto con permiso de dicho Museo.

${ }^{15}$ Las medidas en el contrato, como ya se ha dicho, son 2 varas de alto por 2 varas y media de ancho (es decir, aproximadamente $166 \mathrm{~cm}$ por $207,5 \mathrm{~cm}$ ). Las medidas actuales de la pintura de la Academia son $154 \mathrm{~cm}$ por $211 \mathrm{~cm}$. Estudiando la pintura al natural hemos observado que las medidas del lienzo original han sido reducidas en su altura, probablemente al cambiar y ajustar el bastidor durante el siglo xIx. Así, esas 2 varas de altura $(166 \mathrm{~cm})$ pasan a ser ahora tras la reducción $154 \mathrm{~cm}$.

${ }^{16}$ Pérez Sánchez, A. E.: Real Academia de Bellas Artes de San Fernando. Inventario de las pinturas. Madrid, 1964, pp. 17 y 80 .

${ }^{17}$ Véanse Catálogo de los cuadros, estatuas y bustos que existen en la Real Academia de San Fernando en este año de 1817. Madrid, imprenta que fue de Fuentenebro, 1817; p. 17, n. ${ }^{\circ} 129$. Otra ed., Madrid, en la Imprenta Real, 1819 , p. 20 , n. ${ }^{\circ}$ 149. Otra ed., Madrid, por Ibarra, Impresor de Cámara de S. M., 1821, p. 22, n. ${ }^{\circ} 150$. Otra ed., Madrid, por Ibarra, Impresor de Cámara de S. M., 1824, pp. 34 y 104, n. ${ }^{\circ}$ 16. Otra ed., Madrid, por Ibarra, Impresor de Cámara de S. M., 1829, p. 17, n. ${ }^{\circ}$ 31. Ver además Catálogo del Museo de la Real Academia de Bellas Artes de San Fernando. 1. ${ }^{a}$ ed., Madrid, MCMXXIX (1929), pp. 18-19, n. ${ }^{\circ}$ 13. Tormo y Monzó, E.: «La visita a las colecciones artísticas de la Real Academia de San Fernando». En Cartillas Excursionistas 'TORMO', VII, Academia de San Fernando. Madrid, 1929, p. 27. Este mismo artículo en Boletín de la Real Academia de Bellas Artes de San Fernando, t. XXIII, 1929, p. 15. Wethey, ob. cit., pp. 120 y 209. Azcárate Ristori, J. M. ${ }^{\text {a }}$ (dir.) y Piquero López, M. ${ }^{a}$ A. B. (coord.): Guía del Museo de la Real Academia de San Fernando (Sección B). Madrid, 1991, pp. 5 y 71, n. $^{\circ} 9$.

18 Ponz, A.: Viage de España. T. III. Viuda de Ibarra, Hijos y Compañía. Madrid, MDCCLXXXIX (1789), p. 99 (carta IV, 13). Ceán conoció la obra recién trasladada a la Academia; ver Ceán Bermúdez, J. A.: Diccionario histórico de los más ilustres profesores de las Bellas Artes en España. T. I. Madrid, 1800, p. 220.

${ }^{19}$ Lienzo 2,01 x 1,71 m. Inv. act. n. ${ }^{\circ}$ 1.642. Véanse Museo del Prado. Inventario General de Pinturas. I. La Colección Real. Madrid, 1990, pp. 132, 805, 808 y 819. Díaz Padrón, M.: Museo del Prado. Catálogo de Pinturas I (Escuela Flamenca. Siglo XVII). Madrid, 1975. Vol. láminas, p. 82, n. ${ }^{\circ}$ 1.642. Vol. texto, pp. 120-122. Considerada de Rubens hasta 1974 en que Díaz Padrón la catalogó como original de Van Dyck. Véase Díaz Padrón, M.: «Una Piedad de Van Dyck atribuida a Rubens en el Museo del Prado». En Archivo Español de Arte, varia, t. XLVII, n. ${ }^{\circ}$ 186, abril-junio de 1974, pp. 149-156, láms. I y II. Foto con permiso del Museo Nacional del Prado. Mi agradecimiento a M. ${ }^{a}$ Teresa Vargas Marugán por la gestión fotográfica.

AEA, LXXVII, 2004, 305, pp. 75 a 97 


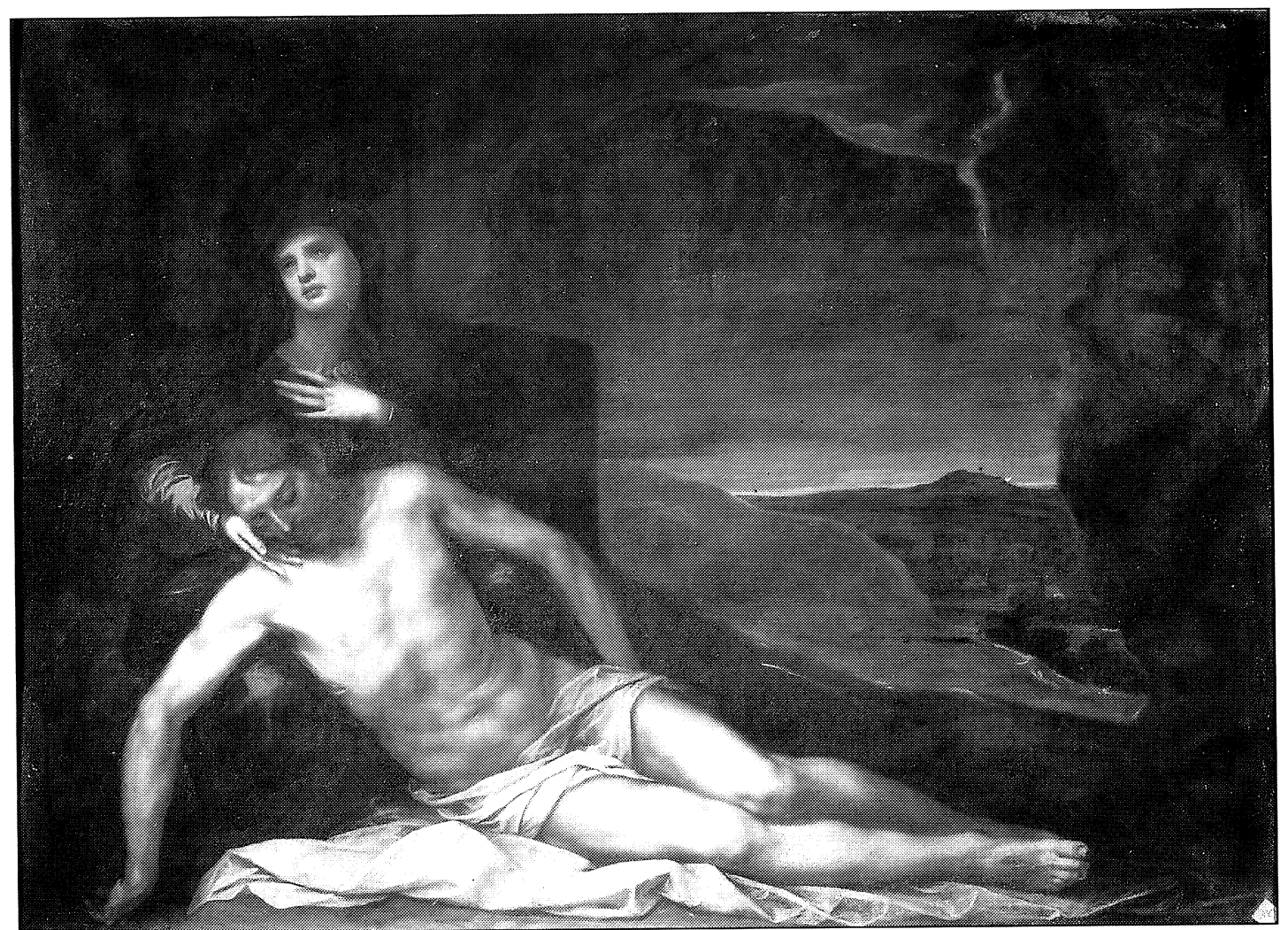

1

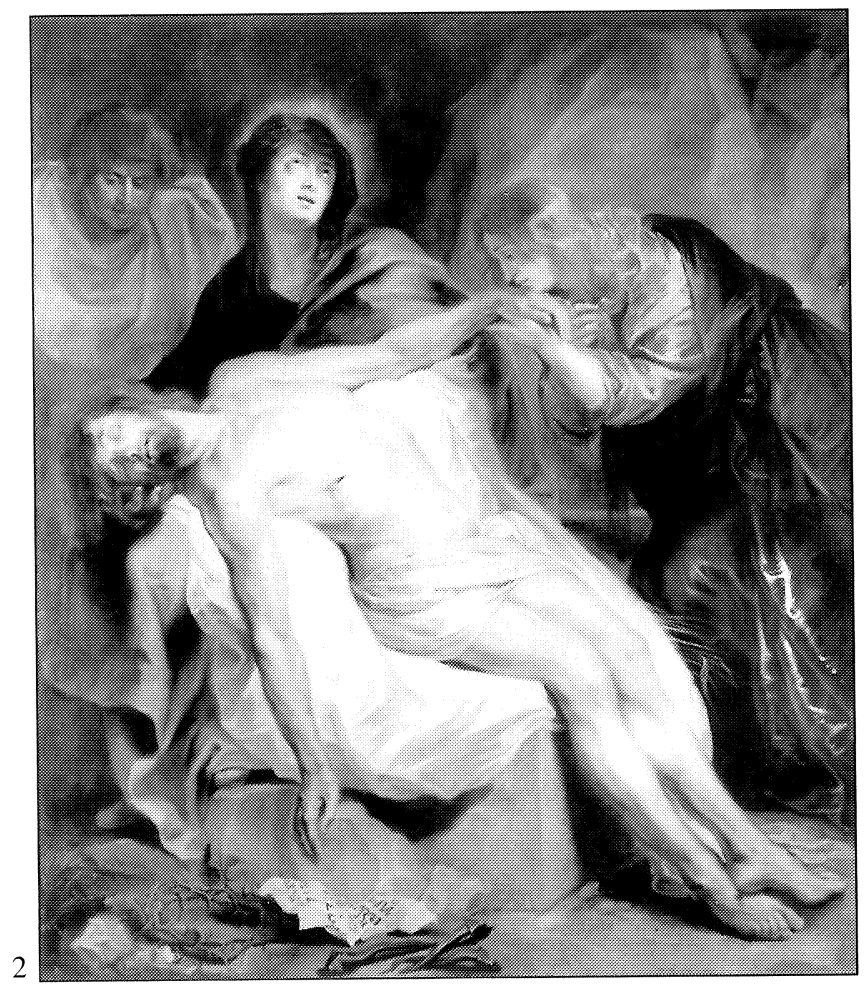

Fig. 1. Piedad. Alonso Cano. Museo de la Real Academia de Bellas Artes de San Fernando. Madrid. Fig. 2. Piedad. Antón Van Dyck. Museo Nacional del Prado. Madrid. 
Sabemos que Velázquez fue la persona encargada de dirigir la decoración pictórica con obras de distinta procedencia con destino a diferentes estancias de este monasterio ${ }^{20}$. Según Bassegoda, la Piedad de Van Dyck era una de las cinco pinturas que decoraban la pared norte del llamado Capítulo Prioral ${ }^{21}$. A falta de mayor documentación desconocemos actualmente la procedencia anterior al monasterio de esta pintura aunque se supone que Felipe IV la envió a El Escorial con posterioridad a $1657^{22}$. Del mismo modo que Alonso Cano acompañó a Diego Velázquez después del incendio del palacio del Buen Retiro madrileño en 1640 por Castilla la Vieja para proveer de pinturas la residencia real, posiblemente Cano acompañó a Velázquez en alguno de sus desplazamientos desde la villa y corte hasta El Escorial para así, por mano de su amigo, conocer de manera directa lo que sería la nueva reorganización decorativa con ciertas nuevas pinturas, procedentes algunas, de las almonedas del rey Carlos I de Inglaterra, de Rubens o de compras o regalos de nobles. Esta hipotética visita de Cano al monasterio podría coincidir con la recepción, precisamente en El Escorial, de un memorial enviado por Cano al rey donde solicita por vacante su paso de racionero a canónigo ${ }^{23}$. En este mismo documento Cano argumenta el haber arreglado pinturas tras el incendio del Buen Retiro, antes citado, además de acompañar «a Diego Velázquez en el viaje que hizo a Castilla la Vieja cuando Vuestra Majestad se lo mandó para efecto de buscar pinturas». El memorial, firmado por Felipe IV, está fechado en San Lorenzo el Real el día 24 de octubre de $1658^{24}$. Es decir, la entrada de Cano en El Escorial en este momento de renovación decorativa podría entenderse como gratitud de Velázquez hacia su amigo por testificar a su favor en las informaciones de hidalguía que por aquellas fechas se realizaban para la concesión del hábito santiaguista al pintor sevillano ${ }^{25}$. De hecho, Cano testifica sobre este asunto el 23 de diciembre de 1658, tan sólo dos meses después del memorial sobre canonjía entregado allí al rey.

El lienzo de la Academia guarda ciertas similitudes con respecto a esta obra. Las condiciones del contrato, dos únicas figuras y formato apaisado, obligarían a Cano a suprimir la representación de San Juan y María Magdalena además de elevar los pies de Cristo, dando así horizontalidad a la obra. El tema se sitúa en ambos lienzos sobre el lateral izquierdo en relación al espectador. La parte superior de ambas tienen correspondencia en el modo de disponer el espacio macizo y vano, de izquierda a derecha, que conforman la gruta. La cabeza, cuello y hombros de la Virgen conservan cierto recuerdo respecto al lienzo del Prado, invirtiendo su situación respecto a un supuesto eje vertical. Una de sus manos reposa sobre su pecho, propuesta que Cano ya utilizó de modo tan personal en su Lamentación del Museo Cerralbo. Este pormenor diferencia en parte la obra del Cerralbo respecto a la estampa modelo de Bolswert, como así lo hace la obra de la Academia respecto de la pintura del Prado. La Virgen, de modo similar al lienzo de Van Dyck, sostiene sobre su muñeca derecha el peso de la cabeza del Redentor. Sus dedos, en ambas obras, no llegan a acariciar el rostro de Cristo muerto. Por último el ocaso, sólo al fondo de la composición en la obra de la Academia, contrasta lumínicamente con su entorno compositivo además de tomar cierto protagonismo dentro de la estructura general del lienzo.

El documento nos permite localizar a Cano en Madrid durante las postrimerías de su segun-

${ }^{20}$ Véase Bassegoda, B.: «La decoración pictórica del Escorial en el reinado de Felipe IV». En La almoneda del siglo. Relaciones artísticas entre España y Gran Bretaña. 1604-1655. Catálogo exposición. Dirigido por J. Brown y J. Elliott. Madrid, Museo Nacional del Prado; del 15 de marzo al 2 de junio de 2002. Madrid, 2002, pp. 107-140.

${ }^{21}$ Ibíd., pp. 134 y 135. Aparece como CP9.

${ }^{22}$ Véase Museo del Prado. Catálogo de las pinturas. Madrid, MCMLXXXV (1985), p. 203, n. ${ }^{\circ} 1.642$.

${ }^{23}$ Pita y Aterido, ob. cit., pp. 377-378.

${ }^{24}$ Ibid., p. 378: «Por parte de Alonso Cano se me ha dado el memorial que va aquí»(rubricado por Felipe IV).

${ }^{25}$ Ibíd., p. 379. Véase Pita Andrade, J. M. (dir.) y Aterido, A. (ed.): Corpvs velazqueño (Documentos y textos). 2 vols. Madrid, 2002; t. I, pp. 381-382.

AEA, LXXVII, 2004, 305, pp. 75 a 97 


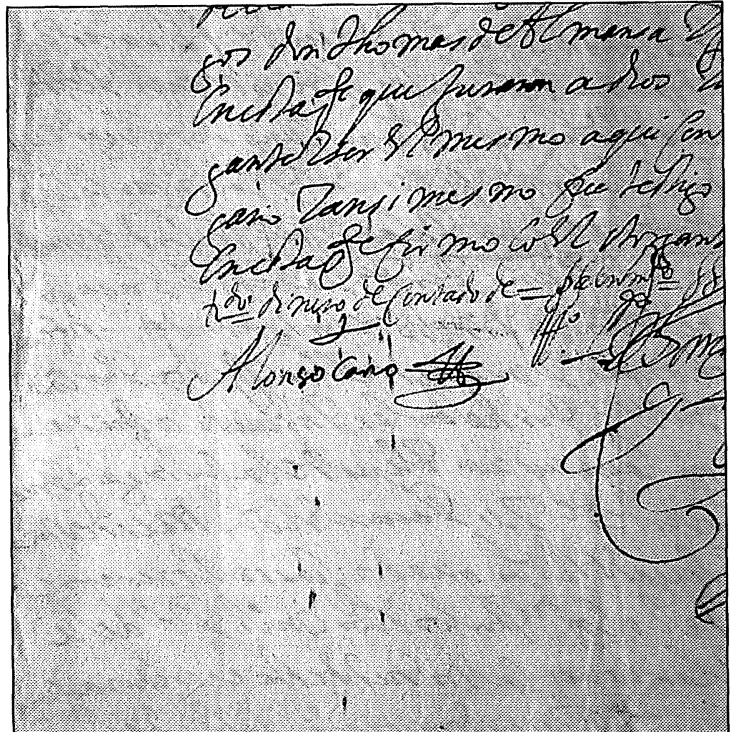

Fig. 3. Firma de Alonso Cano. A.H.P.M., Madrid.

da etapa madrileña, esto es, la considerada entre primavera o verano de 1657 y junio de $1660^{26}$. Su situación inicial sería de apresurado regreso a Granada a causa del reclamo desde el cabildo granadino, con fecha $27 \mathrm{de}$ abril de 1660, por razones de su ya dilatado pleito ${ }^{27}$. Es conocida la ampliación de estancia en Madrid que el embajador inglés solicita para el artista el 1 de junio, días previos a este contrato, para que finalice «una imagen que estaba trabajando para el Rey de la Gran Bretaña mi Señor, con otro cuadro considerable» ${ }^{28}$. Esta carta ejercería mayor peso que otro memorial, menos aireado por los historiadores, elevado tan sólo cuatro días antes del contrato efectuado con Blas López, donde Alonso Cano expone su demora ya que «a negociado en este mismo tiempo le esperen por las deudas que ha contraído para sustentarse en esta Corte, repartiendo los doscientos ducados que le ha entregado el racionero $d$. Diego de Villalobos». Continúa en el mismo documento haciendo referencia a su medio de transporte hacia Granada, donde anuncia «no haber tampoco hallado carruaje a propósito» con lo cual «pide y suplica se sirva de mandar se le conceda otro mes de término para buscar dicho carruaje y acabar de ajustar sus dependencias y llegar a dicha ciudad (Granada)» ${ }^{29}$. Es decir, Cano excusa su marcha desde Madrid a Granada. Cronológicamente entre el tiempo en que se presentan memorial y carta es cuando se efectúa la firma del contrato que aquí nos ocupa (fig. 3) ${ }^{30}$ y que Cano ya tenía previsto realizar en el momento de instar su primera prórroga.

Con respecto al cuadro, como apuntamos al principio, se especifica «entregarlo en esta Corte en casa y poder del dicho Blas López en todo el mes de octubre que viene de este presente año». Pero Cano, al tiempo en que finaliza el plazo de entrega, lleva ya algunos meses en Granada de donde, parece ser, no volverá más a Madrid.

Esperemos que próximas investigaciones y documentos arrojen nueva luz sobre esta cuestión.

\section{Apéndice documental}

«En la villa de $\mathrm{M}^{\mathrm{d}}$ a veynte y ocho días del mes de Mayo del / año de mil y s ss $y$ sesenta ante mi El $\mathrm{p}^{\text {te }} \mathrm{s}^{\text {no }}$ y testigos Pareció / El Lz ${ }^{\mathrm{do}}$ Alonso Cano Razionero de la s ${ }^{\text {ta }}$ Iglesia de Granada / Procurador fiscal de la Cá-

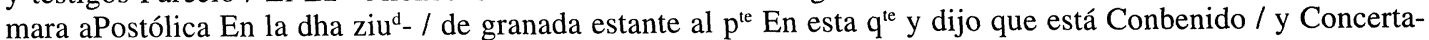
do Con Blas López maestro del arte de escrivir / En que le aya de hazer de Pintura un quadro Con dos figu/ ras La una de nro. s. ${ }^{\text {or }}$ tendido En el Regazo de nra s. ${ }^{\text {ra }}$ que a de ser / la otra figura del dho quadro El qual a

\footnotetext{
${ }^{26}$ Véanse Cruz Valdovinos, J. M.: «Las etapas cortesanas de Alonso Cano». En Alonso Cano. Espiritualidad y modernidad artística, ob. cit., pp. 177-213. Cruz Valdovinos, J. M.: «Encargos y clientes de Alonso Cano en la Corte de Felipe IV». En Alonso Cano. La modernidad del Siglo de Oro español, ob. cit., pp. 73-89.

${ }^{27}$ Pita y Aterido, ob. cit., pp. 399-402.

${ }^{28}$ Ibíd., p. 401.

${ }^{29}$ Ibíd., p. 400. Con fecha 24 de mayo de 1660.

${ }^{30}$ Foto del autor con permiso del A.H.P.M.
}

AEA, LXXVII, 2004, 305, pp. 75 a 97 
de ser de dos baras y / media de ancho y dos baras de Alto. En Prezio de mil $\mathrm{R}^{\mathrm{s}}$ de / V, ${ }^{\text {on }}$ Por cuya Causa el dho Liz ${ }^{\text {do }}$ Alonso Cano se obliga de / hazer El dho cuadro En la forma Referida y Entregarlo En / esta q $^{\text {te }}$ En Casa y poder del dho Blas López En todo El mes / de otubre (sic) que viene de este . $^{\text {te }}$ año Por q $^{\text {to. }}$ le a dado y Pagado / los dhos mil $\mathrm{R}^{\mathrm{s}}$ de vellón En [tachado: dinero de Contado de] dife- / rentes alajas y estampas. y mediante ellas sse dá Por en- / tregado de los dhos mil R ${ }^{\text {s }}$ Por haberlas Recivido a ssu sa- / tisfaz ${ }^{\text {on }}$ y Renunzia la excepcion y leyes de la Entrega y Prue- / ba del Recivo por no ser de $q^{\text {te }}$ y si Pasare El dho Mes de otu/ bre (sic) sin haberle Entregado el dho quadro Consiente ser apre- / miado al Entrego de lo Ex..$^{\text {do }}$ Por los dhos mil Rs a ele- / zion del dho Blas López En Virtud desta escritura sin / otro Recaudo alguno y siendo nezesario salir desta $\mathrm{q}^{\text {te }}$ / a la dha $\mathrm{Ex}^{\text {on }}$ y Cobranza Consiente que a ssu costa se pueda / Inbiar (sic) Persona dondequiera que estubiere o se allaren bienes / suyos Con quinientos mrs de salario En Cada un día de los / que se oCupare En la yda estada y buelta asta la Real / y efetiba (sic) Paga y por lo que ynPortaron los salarios / se le a de Poder hazer la mesma Ex ${ }^{\text {on }}$ que Por El prin // zipal y Renunziala Ultima Premática (sic) que los pro- / bó En los Contratos y Para Cumplirlo ansi obliga su / Persona y Vienes espirituales y tenporales avidos y por / haver y Para que conpelan doy Poder a todos los jue- / zes y justizias que de sus causas Puedan y deban conozer / de qualesquier Partes que sean a quién se somete y En es- / pecial al fuero y jurisdizión del Il, ${ }^{\text {mo }}$ monseñor nun- / cio de su santidad que Reside En esta q $q^{\text {te }}$ y lo Recive por / sentenzia Pasada En Cosa juzgada Renuncia su fuero / las demás leyes de su fabor la general y derechos / della y ansi lo dijo y otorgó ante mi el s. ${ }^{\text {no }}$ siendo testi- / gos don Thomás de Almansa y Juan Ruiz Residentes / En esta q ${ }^{\text {te }}$ que juraron a dios y a una Cruz conozer al otor- / gante y ser El mesmo aquí Contenido sin fraude ni en- / gaño y ansi mesmo fue testigo y Juan Albarez Residente / En esta $\mathrm{q}^{\text {te }}$ firmolo El otorgante y Un testigo de Conozim ${ }^{\text {to }} . /$

Alonso Cano

$\mathrm{tt}^{\mathrm{o}} . \mathrm{d}^{\mathrm{o}}$ Thomas de Almansa

y Laplaza

Ante mi

Pedro de Viana y Morales.

FERNANDO LÓPEZ SÁNCHEZ

\section{NOTICIAS SOBRE UNA OBRA DEL ESCULTOR JUAN DE LEÓN EN ALCALÁ DE HENARES (1760-61)}

La trayectoria vital y profesional de Juan de León no es demasiado conocida, cosa que en los últimos tiempos se ha venido a matizar. Fue originario de Aragón, concretamente de la localidad turolense de Bañón, donde nació y fue bautizado el 11 de junio de 1712. Trasladado a Madrid y activo en la Villa y Corte como escultor desde, al menos, 1743 — año de su primer matrimonio-, con residencia en la parroquia de S. Sebastián de la Corte en 1748, murió el 20 de mayo de 1767, habiendo hecho Declaración de Pobre, y habiéndose casado por segunda vez ${ }^{1}$.

Como ha señalado María Luisa Tárraga, fue en la Corte un escultor muy apreciado en su tiempo. Se le conoce sobre todo por su participación en la elaboración de los sepulcros de la reina Bárbara de Braganza y de su esposo el rey Fernando VI en las Salesas Reales, aunque realizó otras muchas obras escultóricas del entorno artístico cortesano ${ }^{2}$. Trabajó en el Real Sitio de Aranjuez, al menos en alguna ocasión como artífice de chimeneas (1747-48) ${ }^{3}$. Sobresale en su

${ }^{\prime}$ M. L. Tárraga Baldó, «Noticias biográficas de un escultor del siglo xviII: Juan de León», Archivo Español de Arte, 277, 1997, pp. 80-87.

${ }^{2}$ A. Ponz, Viage de España, Madrid, Vda. de Ibarra, 1793, V, p. 256; E. Serrano Fatigati, «Escultura en Madrid desde mediados del siglo XVI hasta nuestros días», Boletín de la Sociedad Española de Excursiones, XVIII, 1910, p. 70; Conde de Polentinos, «El Monasterio de la Visitación de Madrid (Salesas Reales)», Bol. Soc. Esp. Exc., XXIV, 1916, p. 281; Ceán Bermúdez, J. A. Diccionario histórico de los más ilustres profesores de las Bellas Artes en España, Madrid, Viuda de Ibarra, 1800, III, p. 10; E. Tormo y Monzó, Las iglesias del antiguo Madrid, Madrid, 1927; F. J. Portela Sandoval, La escultura en tiempos de Carlos III, Madrid, 1989.

${ }^{3}$ M. L. Tárraga Baldó, Art. cit., pp. 83 y 86. 